\title{
Chaves de casa, chaves de leitura: fragmentos de leitura do romance $A$ chave de casa, de Tatiana Salem Levy
}

\author{
House keys, reading keys: \\ Fragments of reading the novel A chave de casa, by Tatiana Salem Levy
}

\author{
Alessandra Cristina Moreira de MAGALHÃES* \\ Universidade Federal Fluminense (UFF)
}

\begin{abstract}
RESUMO: A partir da leitura do livro A chave de casa, de Tatiana Salem Levy, propomos que se estabeleça com essa obra uma leitura em trânsito. Situando-se no espaço autobiográfico, esse texto provoca uma leitura da dúvida, uma leitura da desconfiança, marcando fronteiras transitórias, visto que essa escrita diz e se contradiz o tempo todo, esgarçando os seus sentidos, alargando a sua própria representação. $\mathrm{O}$ romance é tanto um olhar subjetivo para as experiências vividas quanto uma (re)invenção do próprio sujeito. A subjetividade é marcada pela reflexão sobre a causa da imobilidade da protagonista. Ao que parece, isso faz parte da sua herança. Logo, surge uma pergunta importante: como vamos ler esse texto? A reflexão sobre a escrita de si na literatura contemporânea não está preocupada com a relação entre a obra e a vida dos autores, mas em buscar o diálogo que essa escrita estabelece com o presente, refletindo sobre o próprio conceito de literatura.
\end{abstract}

PALAVRAS-CHAVE: Tatiana Salem Levy. A chave de casa. Escrita de si. Literatura contemporânea

ABSTRACT: Based on the book A chave de casa, written by Tatiana Salem Levy, we propose to establish a transitory reading. This text, placed in an autobiographical space, leads to a reading of doubt, guess, marking transitory limits once this writing states and denies itself all along the way, straining the meanings and widening its own representation. The novel is both a subjective look at real life experiences and a (re)invention of the subject itself. The subjectivity is marked by reflection about the immobility of the protagonist. Apparently, that immobility is part of his inheritance. Therefore, a relevant question arises: how are we going to read this text? The reflection on the self-writing in contemporary literature is not concerned with the relation between the work and the lives of authors but it is seeking the dialogue this writing establishes with the present, thinking about the concept of literature.

KEYWORDS: Tatiana Salem Levy. A chave de casa. Self-writing. Contemporary literature

\section{Introdução}

O presente artigo foi resultado de estudos e pesquisas realizados no curso "Escritas de si na literatura contemporânea", ministrado pela professora Diana Klinger, no primeiro semestre de 2011, no Programa de Pós-Graduação em Estudos de Literatura, da Universidade Federal Fluminense. Tendo em vista a ideia de autoficção, apresento algumas perspectivas de leitura em relação ao romance "A chave de casa", de Tatiana Salem Levy.

\footnotetext{
* Doutoranda do Instituto de Letras, Programa de Pós-Graduação em Estudos de Literatura, da Universidade Federal Fluminense (UFF). Niterói - Rio de Janeiro. Email: alessandrademagalhaes@ yahoo.com.br
} 


\section{Fragmento 1: O romance}

O romance $A$ chave de casa, de Tatiana Salem Levy, foi apresentado, primeiro, como tese de Doutorado ao Programa de Pós-graduação em Estudos de Literatura da PUCRio, A chave de casa: experimentos com a herança familiar e literária. A tese está dividida em duas partes - I. Romance; II. Pós-escrito - além do romance, um ensaio compõe o corpo da tese. O formato do trabalho ensaístico não é nada convencional, pois se estrutura como um "Diário de Bordo" da escritura da tese-romance. Nele, a autora defende que a escolha de apresentar um romance como tese marca uma posição política, visto que isso abriria a Universidade a outras formas de escrita e criação, legitimando, assim, no espaço acadêmico, outras formas de saber e conhecimento - como, por exemplo, o romance, que é uma experiência de saber atravessada pela experiência do sensível - além daquela que vem sendo usualmente praticada. Ainda no pós-escrito, a autora fala sobre a sua herança familiar e literária e sobre o conceito de autoficção, ao qual retornaremos mais adiante.

Em uma entrevista ao programa Letras e Leituras, da Rádio Eldorado, a autora revelou que a ideia de apresentar o romance como tese foi de sua orientadora, Marília Rothier, quando soube que, em paralelo à tentativa de escrever sua tese, Tatiana Salem Levy escrevia um romance. Já o livro, publicado pela Editora Record, é composto de 206 páginas distribuídas em 110 capítulos, sem títulos ou números. Em alguns capítulos, temos apenas algumas linhas escritas e em outros, uma, duas, três, até quatro páginas, não mais do que isso. $\mathrm{O}$ que pode ser entendido como uma pista para o leitor de que esse romance é uma escrita de estilhaços, de fragmentos, conforme acentua, na orelha do livro, Cíntia Moscovich. Esses fragmentos formam um mosaico da busca da protagonista por um sentido à paralisia que toma o seu corpo.

O romance desdobra-se em quatro narrativas, tendo como eixo principal a história da viagem de uma personagem, que recebe de seu avô a chave da casa onde ele morou na Turquia e, por isso, ela embarca para lá em busca de sua herança, do seu passado, mas também de construir o seu presente. Em paralelo a essa narrativa, contam-se também fragmentos das histórias dos antepassados dessa protagonista - do mesmo avô, emigrante judeu, que vem para o Brasil no início do século XX, e da mãe, que, na ditadura militar, exilou-se em Portugal, onde nasceu a protagonista do romance; também há a narrativa da morte da mãe - com quem ela mantém um intenso diálogo; e, ainda, a história de uma relação de amor passional e violenta. Nas palavras da autora, em entrevista já citada, $A$ chave de casa "é um romance de perdas e de buscas e de alguns encontros."

A chave de casa é também um romance de migrações, exílios, viagem, identidades, intimidade, sexo, prazer feminino, amor, violência, dores, herança, escolhas, fantasmas, abandono, retorno, judeus, mal-estar, paralisia, real, ficção, invenção. É, sobretudo, um romance que nos convoca e nos provoca a pensar na relação entre escrita e leitura, ou melhor, na relação entre modos de escrever e modos de ler. Talvez, todos esses caminhos percorridos pelo romance, e também pelo leitor, possam servir como hipótese para o sucesso do livro. O romance foi finalista dos prêmios Jabuti 2008 e Zaffari \& Bourbon de Literatura 2009 e venceu o Prêmio São Paulo de Literatura 2008, na categoria melhor livro de autor(a) estreante. Além disso, foi publicado em Portugal pela Editora Cotovia e também teve tradução para outras línguas. O leitor, mergulhado neste caleidoscópio, anseia pela próxima imagem que irá ver / construir após girá-lo alguns graus. 


\section{Fragmento 2: Recebendo e passando a chave}

Há um tempo, receber a chave de casa era quase um rito de passagem. Quando se recebia a chave, recebia-se junto um voto de confiança, pois se tornava possível entrar em casa a hora que quisesse, tendo a liberdade de abrir a porta sem precisar que houvesse alguém lá dentro para lhe autorizar a entrada. No entanto, isso também trazia a responsabilidade de que se fosse capaz de tomar decisões, fazer escolhas, estar sozinho dentro deste espaço e eleger as companhias que desejava levar para casa, a fim de se compartilhar a sua intimidade.

A casa é um espaço de intimidade. Logo, ao leitor, quando a chave de casa lhe é ofertada pela autora, é dada uma permissão, uma autorização para que ele entre na intimidade de sua escrita e percorra os espaços do processo criativo no seu primeiro romance, no seu romance de estreia.

Ao leitor, são indicadas as pistas para uma leitura circular, talvez espiral e quiçá randômica. Esses modos de ler não são nenhuma novidade quando estamos falando de leituras num século mediado pelas virtualidades, pelos hiperlinks, pelas tantas vozes que comentam um post nas redes sociais ou nos blogs e abrem possibilidade para inúmeras outras narrativas, discussões, questões, imagens, vídeos, para outras vozes e outros discursos.

A escrita deste texto diz e se contradiz o tempo todo, esgarçando os seus sentidos, alargando a sua própria representação. Situando-se no espaço autobiográfico ${ }^{1}$, esse texto dilui fronteiras, virtualizando-as a tal ponto que o leitor não sabe mais os limites, ou mesmo se há limites, entre o que é autor, o que é narrador ou o que é personagem. $\mathrm{O}$ trânsito entre real e ficção é uma das maneiras desse texto de provocar o leitor. ${ }^{2}$ Logo, surgem algumas questões: "Como vamos ler esses textos?" "Vamos buscar na vida dos autores as explicações para cada vírgula?" "Vamos investigar quem foi o seu caso amoroso que inspirou este ou aquele personagem?"

Visto que não é possível situar espaços distintos para o real ou a ficção, a leitura nesta clave não é o caminho a ser seguido. Nesse terreno movediço, a mistura de real e ficção é um jogo da própria literatura. Logo, a reflexão sobre a escrita de si na literatura contemporânea não está preocupada com a relação entre a obra e a vida dos autores, sua investigação busca o diálogo que essa escrita estabelece com o presente.

\section{Fragmento 3: Autoficção e literaturas pós-autômonas}

No livro Escritas de si, escritas do outro: o retorno do autor e a virada etnográfica, resultado de sua tese de doutoramento, Diana Klinger (2007) afirma que a autoficção se situa nos limites da ficção. Essa literatura é uma forma discursiva que exibe o sujeito e, ao mesmo tempo, questiona-o. Neste contexto, tanto a subjetividade como a escritura são vistos como processos em construção. É como se o leitor estivesse vendo se desenrolar sob seus olhos o processo de construção da escrita e do sujeito, que acontecem simultaneamente, dando uma ideia de work in progress, aproximando, assim, a autoficção da performance.

\footnotetext{
${ }^{1} \mathrm{O}$ conceito de espaço autobiográfico está sendo usado conforme o define Leonor Arfuch no livro $O$ espaço biográfico: dilemas da subjetividade contemporânea. Rio de Janeiro: EdUERJ, 2010.

${ }^{2} \mathrm{Na}$ entrevista, já citada anteriormente, ao programa Letras e Leitura, a autora diz o seguinte sobre esse processo: “Muitas vezes as pessoas perguntam: ‘Ah, mas isso aconteceu, isso não aconteceu?'. Enfim, eu não respondo, porque o barato é não saber mesmo. Não importa quando você está lendo o romance o que aconteceu na minha vida, o que não aconteceu. Importa o que está ali acontecendo com o personagem."
} 
Essa escrita deixa à mostra as estruturas de ferro que, em geral, ficariam por baixo do concreto. Coloca-se o próprio processo de escrita não só no esqueleto do texto, mas como corpo dele. E deixa-se corpo e esqueleto visíveis ao leitor. Quer dizer, é o processo de escrita que vai desenhando um sentido para a vida daquele sujeito, que não é pleno, mas fragmentado e, mesmo, incompleto. Este "retorno do autor" - levando em conta a ideia foucaltiana de "morte do autor" - conforme defende a pesquisadora Diana Klinger (2007) em seu livro, implica uma perspectiva em que se faz necessário desvincular autoria de autoridade. Nesses textos, o próprio autor deixa claro para o leitor que não há uma relação do texto com a verdade e que a sua versão da verdade pode não ser nada confiável.

$\mathrm{Na}$ autoficção, não é possível pensar, por exemplo, no autor como aquele que assuma frente ao leitor um compromisso de dizer que está narrando a verdade sobre sua vida. No entanto, no livro de Tatiana Salem Levy, por exemplo, se a protagonista da narrativa não se identifica com a autora, também não se distancia dela. Como nos lembra Diana Klinger (2009, p. 233), em sua resenha do livro,

\footnotetext{
Neta de judeus turcos, Tatiana Salem Levy nasceu em Lisboa, onde os pais estavam exilados por conta da ditadura militar, e veio para o Brasil antes de ter completado um ano de idade. Todos os dados biográficos da escritora se confundem com os da narradora. Ademais, a descrição que a narradora faz de si coincide com a fotografia da autora na orelha do livro [...].
}

Por isso, é possível afirmar que a autoficção questiona, a todo momento, o conceito de que para ser literatura tem que ser "pura ficção", isto é, de que literatura é apenas sinônimo de ficção. Autora, narradora e personagem se imiscuem no corpo deste texto cambiante. Então, o leitor está circulando num espaço-texto movediço e não tem mesmo onde se agarrar. A relação que se estabelece entre texto e leitor é de trânsito, de dúvida, de desconfiança, de suspeição. O que descentraliza a ideia de uma literatura autônoma, conforme defende Josefina Ludmer (2010), no ensaio "Literaturas pós-autônomas". A literatura pós-autônoma borra as fronteiras, ficando numa posição diaspórica - dentro-fora - frente aos parâmetros que definem o que é literatura.

Nas suas próprias palavras,

\begin{abstract}
As literaturas pós-autônomas (essas práticas literárias territoriais do cotidiano) se fundariam em dois (repetidos, evidentes) postulados sobre o mundo de hoje. O primeiro é que todo o cultural (e literário) é econômico e todo o econômico é cultural (e literário). E o segundo postulado dessas escrituras seria que a realidade (se pensada a partir dos meios que a constituiriam constantemente) é ficção e que a ficção é a realidade (LUDMER, 2010, p. 2).
\end{abstract}

\title{
4 Fragmento 4: Vozes em diálogo
}

O constante diálogo que ela estabelece com a mãe já morta, cuja "voz" aparece no texto entre colchetes, problematiza a questão da polifonia no romance, deixando às claras que há outras vozes que o atravessam, além da daquele que narra ou da dos personagens. As falas da mãe não aparecem só no corpo do texto, o próprio corpo da narradora, nos mínimos gestos, às vezes, parece uma continuação do corpo da mãe e do de todos os seus antepassados: "Quando emendo uma gargalhada na outra, por exemplo, e não consigo parar, tenho a certeza de que é você quem está rindo" (LEVY, 2010, p. 49), ela diz em seu diálogo imaginário e póstumo com a mãe. Essa voz materna estabelece com a protagonista 
do romance um movimento de confronto, mas também de afeto, o que podemos ler como uma representação dos conflitos apontados pela psicanálise na relação entre mãe e filha.

Aliás, em diversos momentos do romance, até mesmo pelo formato fragmentado dos seus capítulos, parece que essa escrita, que busca extirpar a dor, poderia ser lida como um jogo de espelhos com sessões de psicanálise. Para Sigmund Freud, na psicanálise o desaparecimento dos sintomas gerados por traumas psíquicos se dá por um processo no qual o paciente é incentivado a falar sobre a sua vida, fazendo associações que indiquem pistas do que ficou recalcado nesta experiência traumática a fim de se "curar" do trauma e, assim, cessar os sintomas (FREUD, 1997). Assim, cada capítulo vai se revestindo das memórias associadas aos momentos traumáticos para curar a narradora do seu sintoma: a paralisia.

A mãe surge como uma voz que a habita, mas que também faz um contraponto às suas dúvidas, aos seus medos, dizendo da necessidade de correr riscos para que aconteçam as mudanças, ou seja, para que a vida dela comece a andar novamente e que seu corpo não seja tragado pela paralisia. Essa outra voz carrega uma força de contestação à forma como a protagonista narra os acontecimentos, apontando que há diferentes maneiras de se contar uma história. Na narrativa do seu nascimento, ela começa os três parágrafos que compõe a única página deste capítulo com a mesma sentença: "Nasci no exílio". No primeiro parágrafo: "Nasci no exílio: em Portugal, de onde séculos antes minha família havia sido expulsa por ser judia. [...]" No segundo parágrafo: "Nasci no exílio, onde meus pais estavam sem querer estar. [...]" No terceiro parágrafo: "Nasci no exílio: e por isso sou assim: sem pátria, sem nome. [...]" É como se ela fosse a terceira geração de uma família que viveu na pele todas as migrações e errâncias de um povo, por isso, ela mesma se sente deslocada, expatriada, longe da terra e de si mesma. Ela se questiona no final desse capítulo: “[...] mas, afinal, quem sou eu? Que terra é a minha?” (LEVY, 2010, p. 25).

Isso foi o que ela herdou, esse deslocamento do próprio sujeito que nunca se sente em casa. As repetições reforçam a ideia de que há um movimento cíclico que a constrói. Sua família, expulsa de Portugal porque seus antepassados eram judeus, instalou-se em Esmirna, na Turquia. De lá, o seu avô viera para o Brasil, após uma grande desilusão amorosa, constituíra uma família e teve sua mãe. A mãe, por sua vez, envolvida no movimento de resistência à ditadura militar brasileira, na década de 70 , foi obrigada a exilar-se em Portugal, onde a protagonista veio a nascer. Depois de alguns meses, seus pais voltaram ao Brasil já com ela nos braços. Pronto, a marca desses trânsitos já havia se instaurado nela. E a própria protagonista empreende a sua viagem, completando o ciclo: do Brasil para a Turquia, da Turquia para Portugal, de Portugal de volta para o Brasil.

E, mais uma vez, apontamos que essa marca também está na construção de sua escrita, que transita pelas diversas narrativas que compõem o romance. A resposta da mãe a essa narrativa dolorida do seu nascimento é circunscrita por uma negação daquilo que acabara de ser narrado por ela pelo prisma da dor: "Não, minha menina, os acontecimentos não foram da maneira que você narra. [...] Você foi muito querida e desejada, a resposta de um exílio sem dor" (LEVI, 2008, p. 26). Como dissemos acima, fica evidente para o leitor que essas fronteiras as quais o sujeito atravessa na sua existência, são fronteiras também atravessadas pela literatura, que suspendem qualquer tentativa de apropriação pelo romance de uma verdade ou de uma realidade. É a própria autora, narradora, protagonista do romance que revela ao leitor que está contandocriando a história: "Conto (crio) essa história dos meus antepassados, essa história das imigrações e suas perdas [...]. Conto (crio) essa história para dar algum sentido à imobilidade, para dar uma resposta ao mundo [...]" (LEVY, 2010, p.62). 
E essa resposta, esse sentido, viria pela narrativa do adoecimento e da morte da mãe, que fica envolta numa névoa de silêncios - "Você escondeu o quanto pôde, evitou a palavra até onde foi possível" (LEVY, 2010, p. 14) -, de medo da morte, de sofrimento, de dor profunda - "Lanço as mãos para o ar como os que não têm razão, como os únicos que têm razão, e repito: abram o caixão" (LEVY, 2010, p. 72) -, mas também de afeto e de entrega - "Tampouco eu conhecia a extensão de nosso sentimento. Era como se o esticássemos a cada dia um pouco e, quanto mais o esticávamos, mais entendíamos que ele iria até onde quiséssemos" (LEVY, 2010, p. 84).

Seria, portanto, essa perda um dos motivos que teria lhe tirado os movimentos, que lhe teria deixado paralisada. É interessante pensar que também seu avô vivera a paralisia, quando recebeu a notícia da morte da mulher amada, de quem havia se afastado por causa do pai dela. Enfim, o motivo de sua vinda ao Brasil. Ao que parece, a paralisia não deixa de ser também uma de suas heranças.

\section{Fragmento 5: Escrita da dor}

Em A chave de casa, já na primeira página do livro, o sujeito que se revela e se constrói na escrita, frente ao leitor, apresenta esse processo de forma paradoxal: "Escrevo sem poder escrever e: por isso escrevo" (LEVY, 2010, p. 9). É, justamente, da impossibilidade que a escrita transborda, porque, neste caso, a escrita representa uma negação do silêncio, uma possibilidade de extirpar a dor. A escrita não se deixa paralisar como o corpo da personagem-narradora, o corpo da escrita é forçado à mobilidade.

Da leitura das primeiras páginas do romance, recolhemos algumas palavras ou expressões que contribuem para essa nossa perspectiva: "não", "sem poder" (p. 9); "inamovível", "imprecisão", "incerteza" (p. 11); "não pôde" (p. 14); "dor" (p. 17); "dor muda", "medo mudo", "ansiedade muda" (p. 19); "desilusão" (p. 20); "culpa", "silêncio" (p. 21); "choro" (p. 22); "tragédia" (p. 23). Ao longo dessas páginas, vão se apresentando ao leitor os leitmotivs do romance: os motivos pelos quais ela escreve; o diálogo com a mãe; a viagem a um lugar, ao mesmo tempo familiar e desconhecido, descobrindo os caminhos de errância e migração de sua família e dela mesma; a doença e a morte da sua mãe, que seria um dos motivos de sua paralisia; o desejo de curar as dores das partidas, das migrações e das perdas que atravessam sua vida. O encontro amoroso, também um dos motivos do romance, não se insere, inicialmente, neste universo de negação, de impossibilidade e de dor, pelo contrário, aparece sob o prisma do prazer e do regozijo. No entanto, mais tarde, a relação de prazer vai dando lugar à violência. Conforme veremos adiante.

Tudo isso vai revelando a busca de um sentido para a sua existência fraturada, imóvel, pétrea, e esse sentido se dará via escrita. Esses leitmotivs se apresentam, como já dissemos anteriormente, a partir das diferentes linhas narrativas que compõem o romance, logo, fica claro que essa busca está em diferentes caminhos que se devem percorrer, não apenas na herança, ou seja, não apenas na chave da casa que ela recebe do avô, mas também em todos os outros aspectos de sua vida e na própria escrita, como ela revela para a mãe: "É, tenho esse sonho impossível: escrever escrever escrever" (LEVY, 2010, p. 108).

\section{Fragmento 6: Amor e violência}

Como um déjá $v u$, ou seja, como algo que se tem a sensação de já ter visto ou vivido antes, esse capítulo, no qual afirma ter sido a morte da mãe o motivo de sua paralisia, reaparece mais adiante. Só que já não é mais a perda do amor materno que a 
imobiliza, mas sim o esgotamento da relação amorosa. Depois do grande prazer que ela sentira, os excessos, as loucuras e a violência que essa paixão provocou causaram-lhe um enorme desgaste ao seu corpo: "Fui perdendo a mobilidade depois que o conheci. Depois que o amei: depois que conheci a loucura através do amor, o nosso. Foi o amor (excedido) que me tirou, um a um os movimentos do meu corpo" (LEVY, 2010, p. 133). O jogo de espelhos entre esses capítulos também nos faz pensar numa representação de Eros e Tânatos, ou seja, amor e morte, juntos, constroem um sentido para a sua paralisia.

É importante reiterar, a essa altura do romance, que o esgarçamento dos sentidos para a paralisia da narradora e protagonista do romance se amplia, mostrando que dizer e, depois, dizer de novo só que de outra maneira, vai se tornando um modus operandi de escrita do romance, dando a entender que esses sentidos se cruzam em algum ângulo das imagens criadas por esse caleidoscópio que o leitor vai girando.

Ao longo da narrativa, o leitor vai acompanhando a metamorfose desse encontro que de libidinoso passa a violento, provocando medo e dor à protagonista. $\mathrm{E}$, na sua narrativa, essa transformação se apresenta no corpo do texto em quatro capítulos que se iniciam com a mesma sentença - "Quando você se aproximou docemente os lábios dos meus ouvidos [...]", mas terminam de forma muito diferente. No primeiro: "[...] sabia que me faria um pedido, amanhã, quero que você [...] vista uma minissaia e não coloque calcinha" (LEVY, 2010, p.105). No segundo: "[...] sabia que me faria um pedido pense numa mulher. [...] E assim fizemos amor durante horas, incansáveis, por todos os cantos da casa, melando o corpo um do outro, o mesmo corpo" (LEVY, 2010, p. 113). No terceiro: "[...] sabia que me faria um pedido, por isso me afastei, estava cansada dos seus pedidos" (LEVY, 2010, p. 119). No quarto, já não há mais nenhum pedido, mas uma ordem: “[...] tive medo, muito medo. Tremi. Tire a roupa. Tire a roupa e me espere na cama, você ordenou" (LEVY, 2010, p. 129).

A narradora, que antes contara inúmeras vezes sobre o seu prazer, passa a narrar a opressão, a tirania desse homem que já lhe havia levado tantas vezes ao gozo ${ }^{3}$. A violência na relação entre os dois chega a um ponto incontornável e a protagonista e narradora se transforma em uma assassina. A nosso ver, esse ato traz a narrativa totalmente para o plano do simbólico. $\mathrm{O}$ vermelho escuro do sangue, que toma conta da cena que a narradora descreve - "[...] o seu corpo era vermelho, o lençol era vermelho. E era esse vermelho que me reforçava a certeza, que me garantia não haver outro final possível para a nossa história" (LEVY, 2010, p. 202) - simboliza, de forma ambivalente, o amor, a paixão, mas também o orgulho, a violência, a agressividade e o poder.

Segundo Chevalier e Gheerbrant (1998), o vermelho, o sangue, se escondido é a condição da vida, no entanto, se espalhado significa a morte. Isso nos faz pensar também no aborto que a protagonista sofrera cuja culpa ela atribuiu ao seu amante. O assassínio deste homem pelas mãos da protagonista, depois de todo o vendaval da paixão e do tormento que foi essa relação, representa, simbolicamente, um ato de libertação. Como num rito de passagem, é essa morte simbólica, representando o fim daquele sentimento, que vai possibilitá-la viver outra vida, livre daquilo que lhe pesava tanto, mais leve. É como se essa morte, ao contrário da morte de sua mãe, empurrasse-a para a mobilidade.

Esse episódio, que é narrado quase no fim do romance, evidencia a impossibilidade de se fazer uma leitura considerando a relação do texto com o real e de que a autora está

\footnotetext{
${ }^{3} \mathrm{O}$ romance expõe de maneira bastante explícita o tema do prazer feminino. Apesar de não ser o nosso viés de análise neste trabalho, parece-nos importante apontar que esse romance, tal como vimos lendo o seu percurso, ao abordar essas questões, vem propor a abertura de um espaço para a reflexão de um domínio ainda notadamente masculino no campo da literatura, porque essa temática do gozo feminino ainda é muito pouco explorada.
} 
contando a verdade sobre sua vida. Diante de um assassinato e de um corpo, a narrativa se tornaria inverossímil se a protagonista, narradora e autora, pelo menos, não respondesse a um processo, não fosse presa ou mesmo conseguisse ficar impune depois da ocultação do cadáver. E o romance já vinha mostrando ao leitor que nada disso acontece.

\section{Fragmento 7: Que viagem interessa?}

A narrativa vai se desenrolando em paralelo à (re)construção desse sujeito que está, ao mesmo tempo, contandocriando sua trajetória para entendê-la e livrar-se daquilo que constitui um peso carregado até o momento. $\mathrm{O}$ tempo da narrativa não coincide com o tempo da vivência, quer dizer, a narrativa vai adentrando os desvãos da memória, que não se submete a um tempo linear. A memória funciona de acordo com a relevância dos acontecimentos que são ressignificados pelo que se é no momento da escrita e não o que se era no momento dos acontecimentos. Ao contar a sua trajetória, ela se reconstrói, vai se transformado e o sujeito junto com ela. Na narrativa do romance, é só aos poucos que o leitor vai costurando essa colcha de retalhos, vai girando esse caleidoscópio e compreendendo o fio descontínuo dessa história.

O fim deste amor que transborda violência também a libera para viver um novo amor, ou seja, é o ato simbólico de matar que vai lhe tirar o peso das costas e dar a leveza necessária para vivenciar, sem medo, o encontro amoroso que acontece na sua viagem, em Portugal, lugar onde nascera e parece que também ela renasce. É justamente esse encontro que leva a narradora a refletir sobre a sua relação com o país de nascimento. Os seus laços não são mais do passado ou estão no passado, eles se renovaram, eles são presentes: "E assim pude partir em paz, voltar para o Brasil com a certeza de que a minha relação com Portugal não era mais uma relação com o passado, nem do passado" (LEVY, 2010, p. 205). Assim como a sua escrita, que mergulha na herança, naquilo que do passado emerge ao presente e edifica a sua construção subjetiva, torna-se, portanto, a escrita do presente.

O romance, que tem início a partir da imobilidade e da dor da protagonista, numa cena em que ela, no seu quarto, (des)escreve sua paralisia, termina neste mesmo espaço. No entanto, aquela narradora que não conseguia sair do lugar, porque "[...] as palavras me escapam, a história ainda não existe" (LEVY, 2010, p. 10), depois de percorrida a sua história e construída a sua escrita e a sua trajetória, já pensa em "botar o cobertor para lavar, tirar as roupas do chão e o mofo das paredes" (LEVY, 2010, p. 206).

Quando o avô entra em seu quarto, no último capítulo do romance, perguntando se ela está pronta para viajar, o leitor já não encontra aquela mesma narradora que iniciou o romance. Ela mesma diz: "Estou enjoada do meu próprio casulo" (LEVY, 2010, p. 206). Não é à toa que ela invoca a imagem desse espaço de metamorfose da lagarta em borboleta. Foi neste espaço do seu quarto, fétido, com musgos na parede e muito mofo, como era o seu próprio corpo, que ela inscreveu incessantemente a sua dor, nas folhas em branco, na sua própria carne, com a sua máquina de escrever - "No centro do corpo, a máquina de escrever. $\mathrm{O}$ teclado quase todo apagado, a tinta por acabar. Minhas mãos enxovalhadas pelo sangue seco teclam, uma a uma, as letras do que escrevo" (LEVY, 2010, p. 40).

O último capítulo coloca para o leitor, mais uma vez, uma interrogação, uma grande dúvida: a viagem à Turquia aconteceu ou não? E, chegando a esse ponto, o leitor compreende que a viagem, na verdade, é uma grande metáfora. Foi partindo desta chave que lhe foi entregue, símbolo da sua herança, que a viagem foi feita, a viagem de si a si mesma, work in progress que toma corpo na sua escrita. Viajar através da escrita é o que põe fim ao seu calvário, ao purgatório da dor e das perdas. A chave, a sua herança, colada 
às mãos da protagonista e do seu avô, sela e separa a sua história da dele. Porque agora, no fim do romance e no fim da narrativa, ela mesma já tem a sua própria história.

\section{Conclusão}

Em A chave de casa, é a escritura que investiga e constrói a subjetividade da narradora e protagonista do romance. Em paralelo, essa mesma escritura, o corpo do texto, está se indagando sobre o conceito de literatura, o percurso da literatura, para que literatura.

No livro Literatura em perigo, Tzvetan Todorov (2010) defende que a literatura tem o papel de ampliar a capacidade de ser humano em cada um, ou seja, de reforçar o caráter de humanidade dos seres humanos. Pode parecer uma proposta tautológica, mas não é. Basta nos lembrarmos de inúmeros fatos que ocorreram nos últimos tempos.

Para Todorov, a função da literatura seria permitir "que cada um responda melhor à sua vocação de ser humano" (TODOROV, 2010, p.24), observando e criando outras realidades diante de si, experimentando a emoção, a sensibilidade, o prazer e, até, a felicidade. No entanto, no mesmo livro, o autor anuncia que a literatura vem sendo reduzida a estudos e análises histórico-literárias, onde o texto é um objeto que se coloca a serviço de outras vozes, ficando, portanto, ele mesmo, silenciado, sendo lido e examinado, como o é um doente pelo médico. É preciso descobrir os vírus ou bactérias que o atacam e receitar um remédio para sarar os seus males.

Sendo assim, o presente artigo pretendeu se apresentar como uma voz ao lado do romance, deixando que também o texto literário falasse um pouco por si mesmo.

\section{REFERÊNCIAS}

ARFUCH, L.. O espaço biográfico: dilemas da subjetividade contemporânea. Rio de Janeiro: EdUERJ, 2010.

CHEVALIER, J.; GHEERBRANT, A. Dicionário de símbolos: mitos, sonhos, costumes, gestos, formas, figuras, cores, números. Rio de Janeiro: José Olympio, 1998.

FREUD, S. Cinco lições de psicanálise. Contribuições à psicologia do amor. Rio de Janeiro: Imago, 1997.

KLINGER, D. I. Escritas de si, escritas do outro: o retorno do autor e a virada etnográfica. Rio de Janeiro: 7Letras, 2007.

KLINGER, D. I. A Chave de Casa (resenha). Revista Scripta, Belo Horizonte, v.23, 2009.

LEVY, T. S. A chave de casa. Rio de Janeiro: Record, 2010.

LEVY, T. S. A chave de casa: experimentos com a herança familiar e literária. Tese (Doutorado) - PUC-Rio. Departamento de Letras. Programa de Pós-graduação em Estudos de Literatura. Rio de Janeiro, 2007.

LEVY, T. S. Entrevista ao programa Letras e Leituras. Rádio Território Eldorado. Áudio. Disponível em: <http://www.letraseleituras.com.br/entrevistas/?a=tatiana_salem_levy>. Acesso em: 10 jul. 2011. 
LUDMER, J. Literaturas pós-autônomas. Sopro: panfleto político-cultural, n. 20, jan. 2010. Disponível em: <http://www.culturaebarbarie.org/sopro/outros/posautonomas.html>. Acesso em: 10 abr. 2011.

TODOROV, T. A literatura em perigo. Rio de Janeiro: DIFEL, 2010.

Recebido em: 12 de janeiro de 2012.

Aprovado em: 15 de junho de 2012. 